\title{
Prof. Howard L. McLeod: passion, teamwork, sense of mission to make pharmacogenomics go out and benefit everyone
}

\author{
Grace S. Li, Anne Y. Lu \\ PRPM Editorial Office, AME Publishing Company \\ Correspondence to: Grace S. Li; Anne Y. Lu. PRPM Editorial Office, AME Publishing Company. Email: prpm@amegroups.com.
}

Received: November 09 2021. Accepted: January 152022.

doi: 10.21037/prpm-2021-03

View this article at: https://dx.doi.org/10.21037/prpm-2021-03

\section{Editor's note}

Pharmacogenomics has progressed significantly in the past few years. However, more research is needed to reveal the gene-drug relationships for clinical guidance. To fill the gap in the knowledge, Pharmacogenomics Research and Personalized Medicine (PRPM) was born with the mission of facilitating the international research around pharmacogenomics and disease genome to benefit patients from personalized medicine.

We interview the Editor-in-Chief of PRPM, Prof. Howard McLeod, to share his reflection on the development pharmacogenomics and ideas on PRPM.

\section{Expert introduction}

Dr. Howard McLeod is Medical Director, Precision Medicine for the Geriatric Oncology Consortium and a Professor at the University of South Florida. He has been honored as a 1000 Talent Scholar of China. Dr. McLeod is a recent member of the FDA committee on Clinical Pharmacology and the NIH Human Genome Advisory Council. Dr. McLeod was vice chair for Pharmacogenomics for NCI ALLIANCE clinical trials group for nearly 20 years, overseeing the largest oncology pharmacogenomics portfolio in the world. Dr. McLeod is world-renowned in the research of pharmacogenomics (ranked \#1 USA/\#2 Global), with extensive experience in leading large international scientific research projects. The Institute of Clinical Pharmacology of Central South University is the sub-center in Asia for the international pharmacogenomics project PGENI, founded by Dr. McLeod.

Dr. McLeod has been investigator for more than \$20 million in grants from the National Institutes of Health, and has published over 590 peer reviewed papers in the top medical journals, such as Nature, Science, Cell, New England Fournal of Medicine, Blood, Fournal of Clinical Oncology, Lancet, FAMA, Clinical Pharmacology and Therapeutics, Pharmacogenomics.

Dr. McLeod's research interests focus on cardiovascular pharmacology, tumor pharmacology, pharmacogenomics and functional genomics.

\section{A close look at pharmacogenomics and precision medicine}

PRPM: Pharmacogenomics is often be viewed as "low-banging fruit" for genomic medicine (1). Can pharmacogenomics be a "sweet spot" for the precision medicine?

Prof. McLeod: Yes. Firstly, pharmacogenomics is a type of precision medicine. And the goal of precision medicine is to diagnose, treat and manage patients in a more personal way than people normally do. Pharmacogenomics and precision medicine are closely linked together. Now research in pharmacogenomics is maturing, but precision medicine is also developing applications using proteins and other tools to manage patients.

PRPM: What is the role of pharmacogenomics in precision medicine?

Prof. McLeod: There are three roles of pharmacogenomics in precision medicine-planning from the start, choosing medicines and solving the basis for bad effects.

The first one is a preemptive role, through which we can know information about a patient before we prescribe 
medicines for them. Therefore, if we do pharmacogenomics early in the patient's life, we are more likely to pick the right medicine from amongst a number of possible medicine choices. The second role is that pharmacogenomics helps patients prioritize or deprioritize some medicine so that they can select them more carefully from a number of the options. The last one is to diagnose why an adverse drug reaction happened. And patients can then avoid that type of medicine and we can move forward with their care.

\section{PRPM: How would you comment on the development of pharmacogenomics in the past decade?}

Prof. McLeod: Ten years ago, pharmacogenomics was considered a research tool. We were doing studies to discover why a medicine might do well in some patients but poorly in others. We were discovering pharmacogenomic markers. We were understanding mechanisms behind pharmacogenomic variations and why these variations cause low enzyme activity. And we were looking at impact of those variants on pharmacokinetic variables and some of "intermediate biomarkers" as they are called. Over time, we have got more information on what we should actually do with the results. Today we apply pharmacogenomics in routine clinical care. Not in every situation by far, but in many situations. But ten years ago, we had no routine application and they were mainly research efforts back then.

\section{PRPM: Do you think the knowledge coverage of pharmacogenomics has expanded with its development?}

Prof. McLeod: Yes. We still have a long way to go, but we have seen the knowledge around pharmacogenomics change quite a lot. Not only are we finding genes, but also understanding why the gene variations are important.

We are understanding which gene variations are most impactful in different populations around the world. We're seeing in some cases that a gene variation might affect one medicine differently than a different medicine, even though they're both metabolized by the same enzyme.

And we are also now trying to look more broadly. Only about 50 of the top 200 prescribed medicine have strong pharmacogenomic studies and the rest of them have not been studied very well. Thus, there is a lot of discovery work, validation work and implementation work to be done. In a word, our knowledge has increased a lot, but we want to increase even more over the next ten years.

\section{PRPM: When do you think will be the era of genomic medicine?}

Prof. McLeod: We are seeing genomics used for diagnosis of new babies in the neonatal intensive care unit. We are seeing it used to diagnose different diseases in pediatric patients. We are seeing it used as part of prenatal testing for pregnant women. Now the list is expanding more and more.

We are not through that era of genetic medicine, but we are in the early part of the era of genomic medicine.

\section{PRPM: Based on your illustrious achievement in pharmacogenomics, where do your inspirations and passion come from? What are your next research goals?}

Prof. McLeod: I still like to discover new pharmacogenomic issues and I enjoyed that. Also, I like to work in areas where the next big thing lays. Now the model for pharmacogenomics in academic health systems works well. For example, in Xiangya Hospital in Changsha, China, pharmacogenomics is well known and is applied routinely. However, in other hospitals, even those nearby, they may not have the same level of experience. One of the things I am working on a lot now is how we make sure that pharmacogenomics is democratized. It means that everyone can benefit from pharmacogenomics regardless of the geographical location and medical centers that are not very academic and not leading the field of medicine can also benefit from it. Sure, the work involves both telemedicine and efforts to make sure that doctors get the right information back. Doctors do not need to be an expert in pharmacogenomics and they just need to know what to do. So, I am trying to do studies around how we get the information to people and to physicians who are trying to practice in a very under-resourced way.

Ultimately, we hope to make pharmacogenomics go out and become a useful tool rather than some fancy thing that only people at big hospitals can use, so everyone will benefit.

\section{PRPM: What would be your advice for a young physician who are going to undertake pharmacogenomics?}

Prof. McLeod: I would say that you have chosen something that will challenge you and be fulfilling for many years to come. And my advice is to find the passion in pharmacogenomics and then work on it.

Pharmacogenomics has a lot to offer: whether it is discovery all the way through to routine use; whether it 
is computational use or an application in the laboratory; whether it is discovery work or validation work or implementation work. There is something for you. Try to make sure that your science helps people.

\section{Experience in academic arena}

PRPM: You are credited as baving both clinical expertise and basic science expertise "under one roof". Could you please share your experience in balancing both?

Prof. McLeod: It was possible in the past that we could have a laboratory and be doing clinical research at the same time, but now it is very difficult to do both. The only way that I manage to do that is by having talented partners, who have their own thoughts and expertise instead of just doing what I say.

Last night, I was on a video call for an hour in a lab meeting with the folks in a hospital across the world from me. And we were talking through projects and understanding of how things were going. They are some very talented, bright and smart people. Because of those people, I get credit for discovery, clinical expertise, policy and this and that. We work as a group so we can be able to move forward. I'm older and they pretend that I'm the one that did it all. But it is really this talented group that makes it happen.

\section{PRPM: Would you like to give us a general picture on the publication area in pharmacogenomics? Any topics or paper impressed you most in the past two years?}

Prof. McLeod: There has been a couple of different publications that are really across the spectrum. Some of the areas that I have really appreciated are some of the studies that have been done by the group of Jun Yang at St. Jude Children's Research Hospital in Memphis.

Prof. Yang et al. discovered that there were genes more commonly causing adverse drug reactions to thiopurine medicines in white people and genes more commonly the problem in east Asian people (2). And then there were some populations that have both of them. This was a really important discovery to me because it highlighted that once we find a pharmacogenomic marker that is causing an effect, we cannot stop. We should have been paying attention all this time. We should not have been satisfied by finding one reason to explain the adverse drug reaction. We need to ask the question: is this effect being caused by the same gene in all populations? We need to know both information in order to give patients the right dose and the safest dose.

I love the paper and the work that he has done and how it is applied. And now we look for both genes in every patient.

Another area that I really enjoy is from some recent studies of the IGNITE network. There is a paper that just came out last week (3). What the researchers have been doing is looking at different centers using pharmacogenomics routinely, asking questions regarding how the acceptance by clinicians and reimbursement by the payers was conducted, as well as, the ways in which the data could get into electronic medical records. All these are practical questions that no one wants to talk about, for everyone wants to discover a gene or do something big. But these people are looking at the boring, but incredibly useful aspects. And if the boring things do not get figured out and pharmacogenomics do not turn practical, we will never be able to help as many people as possible.

Those are two very different examples, which really inspire me to think differently and to do better work, whether it is research or clinical.

\section{PRPM: How to turn an academic idea into an article?}

Prof. McLeod: I was taught very early on about that. We need to ask ourselves two questions: so what and who cares?

So what is about why it is an important question. If you fail to answer it, your preparatory work or idea may not be good enough. And who cares is about who will be interested in the results if I am successful with my work. Will it be no one or only my mother? Will it be some clinicians or administrators or all clinicians?

These two simple questions are very difficult ones. Once you can understand them, you know how to do the right research. Right research gives birth to a right and clear endpoint. You will know who you audience is. You can write a paper to the audience and publish it in a correct journal for them.

But in some cases, a correct journal may be the one with low impact factor. Nevertheless, to meet the audience, it is a right place for your paper. Take myself for example. I have published almost 600 papers. But some of my favorite papers were not in journals with highest IF but in modest ones. But they reached the right people and changed the field in some way.

A good thesis is about research that is going to change 
something important. If you write a thesis, it may or may not be published. If you write about good science, it will be published and become a good thesis.

\section{PRPM: What do you think constitute a good paper (in pharmacogenomics)?}

Prof. McLeod: Firstly, a good paper should be clear and definitive. It should come to a clear conclusion about something instead of hinting that people should do research over here.

Secondly, a good paper can reach the right audience and change the field. Even though the change may be in mostly small ways, but we still want to change it.

I do not like it when people say that for a job application or a raise in salary they would like to publish in a high impact journal. I believe that good studies published in appropriate places can still make for a very nice career.

\section{Being the co-Editor-in-Chief of PRPM}

\section{PRPM: What do you think is important for starting up a journal?}

Prof. McLeod: Currently, there are many journals out there. It is important to understand what the unmet needs are. First, a peer-review journal needs to be done in a way where a relatively rapid time period between submission and a peer review answer is ensured.

Make sure that the review process is not the same as all the other journals. I personally think the editors should do the first review so that only the high-quality papers are sent for reviews.

For one thing, it is important to shorten the manuscript turnaround time. Especially if it is an online journal, rapid turn-around time for the full process matters a lot. Those manuscripts that do not fit our journal should be rejected quickly from the very start, so the authors can submit their work to another, more appropriate journal without having to wait for weeks.

For another, it can increase the efficiency of review process and the quality of expectation. When a reviewer receives the manuscript, they would say "oh, this is a really good paper and this is a good journal." In turn, the reviewer may be more willing to publish in the journal as they believe in the quality of the journal.

Secondly, keep a balance between charges made and the cost of publishing. There are many journals over there that are very expensive. It does cost money to run a journal and try to make sure there are enough money to run the journal, but not so much that it seems like a moneyoriented "predatory journal." Because people would usually expect a new journal as a predator until it is showing not as a predator. There is not a need for bottom journals but a need for some good quality journals.

Therefore, high quality journal means high quality science, professional but quick review and so on.

\section{PRPM: What would you expect to see in PRPM?}

Prof. McLeod: It is noted that PRPM is just a new journal and we are not going to get the most amazing discovery papers which prefer journals with higher impact. However, high-quality discovery papers will have a place in PRPM. What's more, we need to be really careful not to publish poor-quality studies that disturb pharmacogenomics. PRPM welcomes good clinical-oriented discoveries.

Secondly, it is important to have a place for case reports which really help expand the field since there are few journals for this type of paper now. People can write up a single interesting case, or a small series of cases as almost a short paper. This would be a place where they could do that.

PRPM welcomes good clinical-oriented discoveries.

\section{PRPM: How would you imagine the uniqueness of PRPM for authors? How can it better serve the physician community?}

Prof. McLeod: Quality is the first priority of our PRPM, which can differentiate from most of other journals and help serve physician community. Our journal may not be the top of the top like Science, Nature or Cell, but it can still to a great extent serve pharmacogenomics.

There would be opportunities for papers that are more important for clinicians, such as position papers and guideline papers. And we hope to pull people and good papers together on clinical practice guidelines for knowledge. By publishing national and international guidelines, PRPM can have a high impact.

At the same time, the editors of PRPM need to purposeful, trying the best to make sure there are important articles of high-quality programming which clinicians cannot get otherwise. 


\section{Acknowledgments}

We would like to thank Prof. Howard L. McLeod for sparing time for the interview.

Funding: None.

\section{Footnote}

Provenance and Peer Review: This article was commissioned by the editorial office, Pharmacogenomics Research and Personalized Medicine for the series "Meet the Professor". The article did not undergo external peer review.

Conflicts of Interest: Both authors have completed the ICMJE uniform disclosure form (available at https://prpm. amegroups.com/article/view/10.21037/prpm-2021-03/coif). The series "Meet the Professor" was commissioned by the editorial office without any funding or sponsorship. GSL and AYL report that they are full-time employees of AME publishing company (publisher of the journal). The authors have no other conflicts of interest to declare.

Open Access Statement: This is an Open Access article

doi: 10.21037/prpm-2021-03

Cite this article as: Li GS, Lu AY. Prof. Howard L. McLeod: passion, teamwork, sense of mission to make pharmacogenomics go out and benefit everyone. Pharmacogenomics Res Pers Med 2022. distributed in accordance with the Creative Commons Attribution-NonCommercial-NoDerivs 4.0 International License (CC BY-NC-ND 4.0), which permits the noncommercial replication and distribution of the article with the strict proviso that no changes or edits are made and the original work is properly cited (including links to both the formal publication through the relevant DOI and the license). See: https://creativecommons.org/licenses/by-nc-nd/4.0/.

\section{References}

1. Roden DM, McLeod HL, Relling MV, et al. Pharmacogenomics. Lancet 2019;394:521-32.

2. Suiter CC, Moriyama T, Matreyek KA, et al. Massively parallel variant characterization identifies NUDT15 alleles associated with thiopurine toxicity. Proc Natl Acad Sci U S A 2020;117:5394-401.

3. Duarte JD, Dalton R, Elchynski AL, et al. Multisite investigation of strategies for the clinical implementation of pre-emptive pharmacogenetic testing. Genet Med 2021;23:2335-41.

(Interviewers: Grace S. Li, Anne Y. Lu, prpm@amegroups.com) 